\title{
ADOÇÃO HOMOPARENTAL, MELHOR INTERESSE DA CRIANÇA E RELAÇÕES DE PODER: UMA ANÁLISE A PARTIR DA TEORIA DE MICHEL FOUCAULT
}

\author{
Thiago Augusto Galeão de Azevedo ${ }^{1}$ \\ Lorena Araújo Matos ${ }^{2}$
}

Resumo: Trata-se de um estudo sobre a adoção homoparental à luz da teoria de Michel Foucault, mais especificamente da sua ideia de dispositivo de sexualidade. Busca-se compreender as concepções subjacentes ao questionamento da adoção homoparental poder representar o melhor interesse da criança, em uma situação concreta. Para tanto, inicialmente, expõe-se o princípio do melhor interesse da criança, seguido de uma explanação sobre a teoria de Michel Foucault e seu dispositivo de sexualidade. E, em um terceiro momento, a partir da construção teórica crítica construída analisar a adoção homoparental no ordenamento jurídico pátrio.

Palavras-chave: Adoção Homoparental; Relações de Poder; Melhor interesse da criança; Dispositivo de sexualidade; Marginalização de vidas.

\section{HOMOPARENTAL ADOPTION, BETTER CHILD INTEREST AND POWER RELATIONSHIPS: AN ANALYSIS ACCORDING MICHEL FOUCAULT'S THEORY}

Abstract: This is a study on homoparental adoption in the light of Michel Foucault's theory, more specifically his idea of a sexuality device. It seeks to understand the conceptions underlying the questioning of homoparental adoption to be able to represent the child's best interest, in a concrete situation. For that, initially, the principle of the best interest of the child is exposed, followed by an explanation about Michel Foucault's theory and his sexuality device. And, in a third moment, from the critical theoretical construction constructed, analyze the homoparental adoption in the national legal system.

Keywords: Homoparental Adoption; Power relations; Child's best interest; Sexuality device; Marginalization of lives.

\section{INTRODUÇÃO}

\footnotetext{
${ }^{1}$ Pós-doutorando em Direito Universidade de Brasília (UNB); Doutor em Direito - Universidade de Brasília (UNB); Mestre em Direito - Centro Universitário do Estado do Pará (CESUPA); Especialista em Direito Civil Pontifícia Universidade Católica de Minas Gerais (PUC-MG); Especializando em Direito Homoafetivo e Gênero - Universidade de Santa Cecília (UNISANTA); Professor da Universidade Federal de Mato Grosso - Campus Araguaia; Advogado (OAB/MT 26.888-B). Coordenador do Projeto de Pesquisa Corpo, Gênero e Relações de poder, em uma interface com o Direito. Endereço Postal: Rua Valdir Rabelo, 485, ap. 201, Barra do Garças Mato Grosso, CEP 78600-011. E-mail: thiagogaleao@hotmail.com.

${ }^{2}$ Doutoranda em Direito pela UNISINOS. Mestra em Direito Constitucional pelo Instituto Brasiliense de Direito Público. Especialista em Direito Penal e Processo Penal (Damásio). Pós-Graduanda em Direito Homoafetivo e de Gênero. Professora no Centro Universitário Estácio de Brasília. Advogada. Endereço Postal: SHCES, QUADRA 605, BLOCO A, AP 203. Brasília-DF. E-mail: 1.maatos@gmail.com
} 
O presente artigo parte de um questionamento disseminado socialmente sobre a possibilidade de uma adoção homoparental representar o melhor interesse de uma criança. Problematiza-se, a partir do presente estudo, o citado questionamento à luz de uma análise baseada na teoria de Michel Foucault, principalmente a partir de seu dispositivo de sexualidade.

Busca-se compreender em que medida o questionamento da possibilidade da adoção homoparental concretizar o melhor interesse da criança é uma materialização da reprodução de relações de poder incidentes sobre a sexualidade?

Mais especificamente, problematiza-se a própria necessidade de investigação de que a adoção homoparental pode concretizar o melhor interesse de uma criança, considerando a sociedade misógina, preconceituosa e homofóbica que vivemos, em que um Ministro da Educação do país afirma que gays vêm de famílias desajustadas [sic]. Apenas a dúvida sobre a adoção homoparental já apresenta fortes indícios de reprodução de preconceitos e exclusões sobre orientações sexuais que não são reproduzidas em sociedade como naturais e normais.

Para tanto, o presente artigo está dividido em três seções. Inicialmente, expõe-se brevemente o princípio do melhor interesse da criança, com o objetivo de apresentar um conteúdo base ao leitor, para que o mesmo possa compreender as discussões travadas neste artigo.

Em um segundo momento, apresenta-se uma análise teórica à luz de Michel Foucault, analisando-se o dispositivo de sexualidade e a sua correlação para com a produção da ideia de sexualidade divergentes e a medida que estas são atravessadas por preconceitos, exclusões e marginalizações.

Para que, em um terceiro momento, possa-se analisar criticamente o tratamento dado à adoção homoparental no Brasil e a sua correlação para com a reprodução de relações de poder, propiciadoras de marginalizações àqueles que não reproduzem a lógica heteronormativa.

\section{PRINCÍPIO DO MELHOR INTERESSE DA CRIANÇA}

Inicia-se o presente artigo com uma breve apresentação do princípio do melhor interesse da criança, que é fruto da necessidade de dar primazia aos interesses da criança. 
Cabe à família, ao Estado e à sociedade promover a efetivação destes interesses. A partir deste princípio qualquer decisão a ser tomada deve levar em consideração o interesse da criança (LÔBO, 2010).

O referido princípio é aplicado, principalmente, no âmbito das discussões familiares, sobre guarda e adoção, por exemplo, quando se deve levar em consideração, para a sua concessão, o melhor interesse da criança, esta como um ser em formação.

A análise do que é melhor para a criança é feita casuisticamente. Neste sentido Silva Pereira (apud, DELFINO, 2009, p.20):

Tânia da Silva Pereira destaca que: '(...) princípio do melhor interesse deve ser analisado em cada caso de litígio sobre a guarda da criança. Na realidade, se a criança for suficientemente madura, os Tribunais devem considerar a sua preferência.' Ademais, assevera a autora: 'a necessidade de se levar em conta a pessoa com quem a criança (...) mantém laços mais fortes de afetividade e carinho (...).'

Extrai-se da referida citação, que a aplicação do princípio do melhor interesse da criança irá variar de acordo com cada situação em análise, uma vez que surtirá efeitos de inúmeras maneiras, a depender do panorama factual em que é aplicado.

Ainda à luz das ponderações realizadas pela referida doutrinadora, percebe-se, muitas vezes, que a garantia do melhor interesse da criança está baseada na sua própria vontade. Porém esta ideia pode estar, completamente, equivocada em uma situação diversa, como por exemplo, no caso de uma criança, que como fruto de alienação parental por parte de sua mãe, rejeita seu próprio pai, que é a pessoa mais adequada para assegurar a proteção dos seus direitos, consequentemente, proporcionar a realização de seu melhor interesse.

$\mathrm{Na}$ referida situação, assegurar o princípio do melhor interesse da criança não significa levar em consideração a vontade da mesma, pois a referida vontade está eivada de vícios, de imparcialidade, frutos de um instituto repudiado pelo Direito, principalmente pelo Direito de família, o instituto da alienação parental.

A Constituição Federal, em seu artigo 227, tutela este princípio:

Art. 227. É dever da família, da sociedade e do Estado assegurar à criança, ao adolescente e ao jovem, com absoluta prioridade, o direito à vida, à saúde, à alimentação, à educação, ao lazer, à profissionalização, à cultura, à dignidade, ao respeito, à liberdade e à convivência familiar e comunitária, além de colocá-los a salvo de toda forma de negligência, discriminação, exploração, violência, crueldade e opressão. 
O mosaico de direitos previstos no referido artigo representa o melhor interesse da criança, que, como já relatado no início, deve ser garantido pela família, Estado e pela sociedade. O princípio em tela, também, é tutelado pela Convenção Internacional dos Direitos da Criança:

Art.3. 1 - Todas as ações relativas às crianças, levadas a efeito por instituições públicas ou privadas de bem-estar social, tribunais, autoridades administrativas ou órgãos legislativos, devem considerar, primordialmente, o melhor interesse da criança.

2 - Os Estados Partes comprometem-se a assegurar à criança a proteção e o cuidado que sejam necessários ao seu bem-estar, levando em consideração os direitos e deveres de seus pais, tutores ou outras pessoas responsáveis por ela perante a lei e, com essa finalidade, tomarão todas as medidas legislativas e administrativas adequadas.

3 - Os Estados Partes certificar-se-ão de que as instituições, os serviços e os estabelecimentos encarregados do cuidado ou da proteção das crianças cumpram os padrões estabelecidos pelas autoridades competentes, especialmente no que diz respeito à segurança e à saúde das crianças, ao número e à competência de seu pessoal e à existência de supervisão adequada.

Desta forma, percebe-se que não apenas a Constituição Federal está preocupada em tutelar os interesses da criança, uma vez que há legislações internacionais neste sentido, preocupadas com os interesses das referidas, que, indiscutivelmente, possuem um caráter essencial e primordial.

\section{DISPOSITIVO DE SEXUALIDADE: PRODUÇÃO DE MARGINALIDADES}

A aplicação do princípio do melhor interesse da criança ao objeto do presente artigo influi na premissa de que a adoção homoparental, aplicada em uma determinada situação concreta, preenchidos os requisitos legais e possibilidades materiais da garantia dos direitos da criança, seja uma materialização do melhor interesse da criança.

Mas é interessante analisar a necessidade de discutir, de dissertar sobre algo que deveria ser óbvio em sociedade, porém não é, considerando uma sociedade doente e extremamente preconceituosa para com sexualidades que são consideradas divergentes do dito normal [sic], sexualidades divergentes da heteronormatividade.

Em outras palavras, o presente estudo só faz sentido justamente por estarmos inseridos em uma sociedade marcada por preconceito e estigmas, que exigem de nós a 
discussão e a reiteração da garantia do melhor interesse da criança a partir da adoção por pessoas que podem propiciar um lar saudável e seguro, sendo homoafetivos ou não.

É preciso compreender, ainda que brevemente, a construção desses estigmas e preconceitos para com modelos de família compostos por pessoas com sexualidades que não são servientes a uma lógica heteronormativa de poder. Para tanto, escolhe-se ressaltar a teoria do dispositivo de sexualidade, do filósofo Michel Foucault.

Para Foucault (2014), o dispositivo de sexualidade foi o responsável pela criação e instauração da ideia de sexo, fazendo este aparecer a partir de quatro formas: a histeria da mulher, o onanismo, o fetichismo e o coito interrompido. $\mathrm{O}$ sexo submetido ao jogo do "todo e da parte, do princípio e da falta, da ausência e da presença, do excesso e da deficiência, da função e do instinto, da finalidade e do sentido, do real e do prazer" (Foucault, 2014, p. 168); formando-se, paulatinamente, uma teoria geral do sexo.

Tal teoria se tornou indispensável para o dispositivo de sexualidade, diante das suas três funções. A primeira delas se trata do papel de agrupamento exercido pela noção de sexo. Este como uma unidade artificial de "elementos anatômicos, funções biológicas, condutas, sensações e prazeres" (Foucault, 2014, p.168).

Sua segunda função foi funcionar como um princípio causal, como um elemento onipresente, como um segredo a ser descoberto em todos os lugares. Assim, nas palavras de Foucault, "o sexo pôde, portanto, funcionar como significante único e como significado universal" (Foucault, 2014, p. 168).

Por fim, permitiu-se o contato entre a sexualidade humana e as ciências biológicas da reprodução. Esse contato, essa "vizinhança", termo foucaultiano, entre os citados saberes, fez com que a sexualidade humana ganhasse um status de quase cientificidade, através de analogias frágeis realizadas e por poucos conceitos transplantados. Foucault (2014) destaca que através da mesma "vizinhança", conteúdos da biologia e da fisiologia contribuíram para normalizar a sexualidade humana.

A noção de sexo produziu uma "reversão essencial", que permitiu travestir a relação positiva, entre poder e sexualidade, de uma relação negativa, no sentido de que o poder sujeitaria a sexualidade, ou seja, o poder seria o responsável por uma repressão da sexualidade (FOUCAULT, 2014).

A partir de uma natureza biológica, “a ideia 'do sexo' permite esquivar o que constitui o 'poder' do poder" (2014, p. 169). Em outras palavras, considerando o sexo como um 
elemento natural este não aparece como construção, como objeto atravessado pelo dispositivo da sexualidade. O poder aparece apenas em sua versão de interdição, de lei.

Entretanto, para Foucault o sexo é um elemento imaginário produzido pelo dispositivo de sexualidade, é "[...] o elemento mais especulativo, mais ideal e igualmente mais interior, num dispositivo de sexualidade que o poder organiza em suas captações dos corpos, de sua materialidade, de suas forças, suas energias, suas sensações, seus prazeres.” (2014, p. 169).

Por este representar um segredo presente em tudo em que os indivíduos são; por este ocultar um sentido, revelador do ser dos indivíduos e libertador daquilo que os define; o sexo além de ser um elemento ideal necessário para o dispositivo de sexualidade e para o funcionamento do mesmo, é o caminho de acesso à inteligibilidade do indivíduo, ao seu corpo e à sua identidade.

Foi através de uma inversão realizada às escondidas, iniciada há muito tempo (época da pastoral cristã da carne), que se chegou ao ponto de procurar a inteligibilidade humana em algo que foi considerado loucura, durante muitos séculos; que se chegou a procurar a inteireza do corpo humano naquilo que foi considerado um estigma e ferida nesse corpo; chegou-se a procurar a identidade humana naquilo que era concebido como "obscuro impulso sem nome" (Foucault, 2014, p. 170).

A partir da criação do citado elemento imaginário, o sexo, o dispositivo de sexualidade suscitou um dos seus princípios internos de funcionamento, dito essencial, o desejo do sexo. Tal desejo inclui o ter, ter acesso ao mesmo, descobri-lo, desbravá-lo, desenterrá-lo, suscitá-lo em discurso, "formulá-lo em verdade". Sobre o desejo do sexo e seu caráter criado, destaca-se as palavras de Foucault (2014, p. 170-171):

É essa desirabilidade do sexo que fixa cada um de nós à injunção de conhecê-lo, de descobrir sua lei e seu poder; é essa desirabilidade que nos faz acreditar que afirmamos contra todo poder os direitos de nosso sexo quando, de fato, ela nos vincula ao dispositivo de sexualidade que fez surgir, do fundo de nós mesmos, como uma miragem onde acreditamos reconhecernos, o brilho negro do sexo.

Em relação à sexualidade e ao sexo, Foucault (2014) comenta que o primeiro é uma "figura histórica muito real", intimamente relacionada ao dispositivo de sexualidade, responsável por suscitar o sexo, como um elemento necessário para o seu funcionamento, um elemento especulativo.

Foucault (2014), atinente à sexualidade e ao sexo, realiza uma inversão na lógica de que a primeira deriva do segundo. Para ele, é o dispositivo de sexualidade que cria e instaura 
o sexo. Em entrevista publicada na obra Microfísica do Poder, as palavras de Foucault sobre tal inversão (2011, p. 258-259):

A.G.: Como você define o que você chama de sexo em relação a este dispositivo de sexualidade? Trata-se de um objeto imaginário, um fenômeno, uma ilusão?

M.F,: Vou dizer a você como as coisas aconteceram. Houve muitas redações sucessivas. No começo, o sexo era um dado prévio e a sexualidade aparecia como uma espécie de formação ao mesmo tempo discursiva e institucional, articulando-se com o sexo, recobrindo-o e mesmo o ocultando. Esta era a primeira linha de análise. Mostrei depois o manuscrito a algumas pessoas e senti que não era satisfatório. Resolvi então inverter tudo. Era um jogo, pois não estava muito seguro... Mas dizia a mim mesmo: no fundo, será que o sexo, que parece ser uma instância dotada de leis, coações, a partir de que se definem tanto o sexo masculino quanto o feminino, não seria ao contrário algo que poderia ter sido produzido pelo dispositivo de sexualidade? $\mathrm{O}$ discurso de sexualidade não se aplicou inicialmente ao sexo, mas ao corpo, aos órgãos sexuais, aos prazeres, à relações de aliança, às relações interindividuais, etc...

J.-A.M.: Um conjunto heterogêneo...

M.F.: Sim, um conjunto heterogêneo que estava recoberto pelo dispositivo de sexualidade que produziu, em determinado momento, como elemento essencial de seu próprio discurso e talvez de seu próprio funcionamento, a idéia de sexo.

Um sexo que não é contemporâneo da instauração do dispositivo de sexualidade. Para Foucault (2011) existe uma sexualidade após o século XVIII e um sexo após o século XIX. Anteriormente, a carne. Assim, a sexualidade não seria derivada do corpo, pelo contrário, ela toma os corpos como seu objeto, sobre o qual incide o seu poder. Investe os corpos com o sexo. O sexo como elemento criado, fruto de um mecanismo de poder, fruto de uma correlação de forças, fruto do dispositivo de sexualidade (Butler, 2008).

Judith Butler, considerada como uma das expoentes da chamada Teoria Queer (apresentação esta que seria, na verdade, contraditória com o que a mesma sustenta, por ser limitativa e definidora) compartilha da concepção foucaultiana sustentadora do sexo como um elemento criado. Para a filósofa (2014) o sexo, assim como o gênero, é produzido culturalmente, não podendo ser considerado uma "substância permanente", tendo em vista que é efeito de uma coerência produzida pela cultura heterossexual, com o intuito de legitimar e manter o que a crítica feminista Adrienne Rich chamou de "heterossexualidade compulsória" 3 (SALIH, 2013).

\footnotetext{
${ }^{3}$ Consiste em uma ordem hegemônica, que solicita ou mesmo impele homens e mulheres a serem heterossexuais.
} 
Para Butler, inclusive, sexo é gênero, tendo em vista que a distinção entre eles é prejudicada a partir do momento em que se considera que ambos são socialmente criados (2014, p. 25, grifo da autora):

Se o sexo é, ele próprio, uma categoria tomada em seu gênero, não faz sentido definir o gênero como a interpretação cultural do sexo. $O$ gênero não deve ser meramente concebido como a inscrição cultural de significado num sexo previamente dado (uma concepção jurídica); tem de designar também o aparato mesmo de produção mediante o qual os próprios sexos são estabelecidos. Resulta daí que o gênero não está para a cultura como o sexo para a natureza; ele também é o meio discursivo/cultural pelo qual a 'natureza sexuada' ou 'um sexo natural' é produzido e estabelecido como 'pré-discursivo', anterior à cultura, uma superfície politicamente neutra sobre a qual age a cultura. [...].

O gênero como elemento decorrente do mesmo discurso e do mesmo processo de produção cultural do sexo. Assim, o gênero não pode ser considerado uma interpretação cultural do sexo. Para Butler, é essa produção cultural, discursiva, que constrói a ideia de que o sexo é pré-discursivo, ou seja, de que ele é uma superfície natural, neutra, na qual a cultura incide, quando na verdade é tão produzido culturalmente quanto o gênero.

Butler comenta que as identidades de gênero que não se enquadram ao padrão heterossexual compulsório, sistema binário, atestam a sua natureza criada e mantida. A filósofa (2014) cita a/o (x) hermafrodita Herculine Barbin, do século XIX, no sentido de que a sua heterogeneidade corporificada representa uma crítica implícita à "metafísica da substância" 4 e à imposição de categorias identitárias sexuais (SALIH, 2013).

Portanto, para Butler (2014), o sexo, assim como o gênero, é um construto discursivo, elemento produzido e não natural. Sustenta-se a produção de uma matriz heterossexual, de forma que o sexo funciona como um instrumento de controle desse poder, assumindo o papel de uma "grade", um "molde" no qual, ou pelo qual, o sujeito é moldado.

O dispositivo de sexualidade como o elemento criador de um sujeito sexual, um sujeito identificado a partir de sua sexualidade. Quem você é? Não. Passa-se a perguntar "Que ser sexual é você?”. Nas palavras de Foucault (2014b, p. 338):

- É exatamente assim. Na cultura grega, que conhecia os aphrodisia, era simplesmente impensável que alguém fosse essencialmente homossexual em sua identidade. Havia pessoas que praticavam aphrodisia convenientemente, segundo os costumes, e outras que não os praticavam bem, mas o pensamento de identificar alguém segundo sua sexualidade não poderia virlhes à ideia. Foi somente quando o dispositivo da sexualidade estava efetivamente estabelecido, quer dizer, quando um conjunto de práticas,

\footnotetext{
${ }^{4}$ A "metafísica da substância" consiste na crença difundida de que sexo e corpo são "naturais", evidentes.
} 
instituições e conhecimentos havia feito da sexualidade um domínio coerente e uma dimensão absolutamente fundamental do indivíduo, foi nesse momento preciso que a questão 'Que ser sexual é você?' tornou-se inevitável.

Assim, dizer sim ao sexo não possui um caráter subversivo à estrutura de poder, pelo contrário, trata-se de um ato de aderência ao dispositivo geral de sexualidade. A subversão à referida estrutura de poder é incompatível com a noção de sexo. Nas palavras de Foucault, "Contra o dispositivo de sexualidade, o ponto de apoio de contra-ataque não deve ser o sexodesejo, mas os corpos e os prazeres" (2014, p. 171). O filósofo comenta a incitação do discurso sobre o sexo e os mecanismos de poder da sexualidade (2014, p. 172-174):

E lá, onde hoje vemos a história de uma censura dificilmente suprimida, reconhecer-se-á, ao contrário, a lenta ascensão, através dos séculos, de um dispositivo complexo para nos fazer falar do sexo, para lhe dedicarmos nossa atenção e preocupação, para nos fazer acreditar na soberania de sua lei quando, de fato, somos atingidos pelos mecanismos de poder da sexualidade. [...] há vários séculos, fizeram-nos amar o sexo, tornaram desejável para nós conhecê-lo e precioso tudo o que se diz a seu respeito; pelos quais, também, incitaram-nos a desenvolver todas as nossas habilidades para surpreendê-lo e nos vincularam ao dever de extrair dele a verdade; pelos quais nos culpabilizaram por tê-lo desconhecido por tanto tempo. São esses ardis que mereceriam espanto hoje em dia. E devemos pensar que um dia, talvez, numa outra economia dos corpos e dos prazeres, já não se compreenderá muito bem de que maneira os ardis da sexualidade e do poder que sustêm seu dispositivo conseguiram submeter-nos a essa austera monarquia do sexo, a ponto de votar-nos à tarefa infinita de forçar seu segredo e de extorquir a essa sombra as confissões mais verdadeiras.

Ironia desse dispositivo: é preciso acreditarmos que nisso está nossa 'liberação'.

Destaca-se a incitação ao discurso sobre o sexo, a interrogação do mesmo, a fim de se procurar uma verdade em um elemento criado. Finge-se resgatar a sexualidade de uma obscuridade, através dos discursos, hábitos, instituições, regulamentos e saberes da sociedade ocidental. Desobscurecer uma sexualidade que tudo "trazia à plena luz e refletia com estrépito.” (2014, p. 172).

O sexo como um elemento natural, um elemento biológico, uma condição biológica do indivíduo. A sexualidade sendo apenas uma conseqüência do mesmo. O sexo como um elemento inserido em uma lógica biológica coerente, que prega que o indivíduo já nasce com um sexo pré-determinado (BUTLER, 2008). Um dos autores que perpetuam o referido caráter sobre o sexo é Elio Sgreccia (2002, p. 305), que defende:

Manipular a sexualidade para fazê-la tornar-se de sinal oposto equivale então a manipular o patrimônio genético em sentido alternativo: recebe-se o corpo, 
o corpo é o que é; o mesmo se deve dizer da sexualidade. [...] 'O homem deve aceitar livremente a sua natureza como ela é, inclusive o fato de já estar predeterminado. [...] Quem vê a vida à luz da verdade da criação sabe que essa dedução transcendental não é outra coisa senão o dom do ser pessoal e espiritual feito pelo Criador, que dá a vida e a atualização àquele corpo, com aquele sexo, naquela existência marcada pela diferenciação sexual, sem nada tirar das 'causas segundas' e dos processos de procriação e fecundação, mas agindo dentro deles como, de outra parte, age dentro de qualquer potencialidade que realiza.

O autor sustenta que o indivíduo já nasce com um sexo nato, pré-determinado, cabendo a este somente o aceitar. O sexo como um elemento dado e não construído. De forma conseqüencial, e com o intuito de manter uma coerência, defende que a sexualidade é diretamente influenciada pelo sexo, no sentido de que se o indivíduo, por exemplo, nasceu com um pênis, este será considerado macho e, conseqüentemente, homem, tendo prazer em mulheres. Trata-se, indiscutivelmente, de uma lógica heterossexual.

Ainda sobre a relação conseqüencial do elemento sexo e sexualidade, cita-se novamente Elio Sgreccia (2002, p. 304):

Desse pressuposto devemos também concluir que a sexualidade marca igualmente toda a personalidade: é o espírito e o 'eu pessoal' que é homem ou mulher e não apenas o corpo, justamente porque é o espírito (o eu pessoal) que anima, informa e faz viver a corporeidade. Por isso, a pessoa não somente tem um determinado sexo, mas é homem ou mulher. Por isso, toda a vocação pessoal no mundo não poderá se realizar harmonicamente senão aceitando e valorizando aquele determinado modo de ser.

A partir da definição do sexo do indivíduo, este não possui alternativa, deve sustentar uma relação com o sexo oposto, ter uma sexualidade "heterossexual". Trata-se de uma conseqüência do sexo, que definirá a sexualidade, no sentido de se relacionar sexualmente com o dito sexo biológico diferente.

A conseqüencialidade e coerência são aplicadas, também, ao elemento desejo sexual, no sentido de que pelo indivíduo nascer macho e ser considerado do gênero masculino seria coerente que este tivesse desejo sexual por mulheres. Se o indivíduo não sente atração sexual por mulheres, sustenta-se que este foge da normalidade, justamente porque não está inserido na referida coerência. Para Elio Sgreccia (2004, p.109), é o caso da homossexualidade:

Existem várias definições de homossexualidade, entre elas uma que encontra amplo consenso entre muitos autores; trata-se de uma anomalia que consiste no 'desvio da atração afetivo-sexual, pelo qual o sujeito sente atração por pessoas do mesmo sexo, podendo ter relações com ela. [...] A Encyclopedia of Bioethics sublinha que se trata de 'uma condição adquirida que é ao mesmo tempo psicológica e patológica'. 
O desejo sexual como um elemento conseqüencial do sexo e da sexualidade, no sentido de que sentir desejo por uma pessoa do "mesmo sexo" é considerado um "desvio de atração afetivo-sexual”, porque o considerado normal, para esta concepção biológica acerca do sexo, é que o indivíduo sinta o citado desejo por pessoas do "sexo oposto". Por não seguir a referida coerência, considera-se que este é detentor de uma anomalia.

Sobre o sexo como um elemento pré-discursivo, natural, Judith Butler comenta (2014, p.25) que "Na conjuntura atual, já está claro que colocar a dualidade do sexo num domínio pré-discursivo é uma das maneiras pelas quais a estabilidade interna e a estrutura binária do sexo são eficazmente asseguradas”.

Trata-se, portanto, de uma lógica heterossexual. O sexo é construído em um discurso que prega a sua naturalidade e a sua relação conseqüencial com a sexualidade. Uma lógica heterossexual, marcada por dois produtos: macho e fêmea. Estes são os coerentes, tudo o que estiver fora disso é considerado anormal, incompleto, incoerente; devendo ser objeto de controle.

Assim, incita-se o indivíduo a dedicar a sua atenção e preocupação ao sexo, fazendose este acreditar na soberania de sua lei, quando, de fato, o referido indivíduo é atingido pelos mecanismos de poder da sexualidade, uma vez que o sexo é, para Foucault, um elemento criado, serviente ao funcionamento do dispositivo de sexualidade, entendimento este que a presente pesquisa se filia.

Os perversos sexuais se tornaram objeto da medicina, que criou uma patologia orgânica intrínseca às práticas sexuais que não se amoldavam à lógica heterossexual. Estas eram consideradas incompletas, dotadas de uma anormalidade e patologia. Como efeito, a medicina catalogou todas as formas de prazer que destoavam das que eram praticadas através da penetração falocêntrica. O conhecimento e o mapeamento destas eram necessários para que o controle pudesse ser exercido de forma efetiva e total. Classificou-se todas as sexualidades destoantes da lógica dominante heterossexual. Uma medicina classificatória, conforme Fonseca comenta (2002, p. 51):

Antes do final do século XVIII a medicina pode ser considerada uma medicina classificatória. Para este conjunto de saberes a doença consistia numa entidade ideal e devia ocupar um lugar num quadro classificatório de suas espécies. O modelo desta medicina é aquele da história natural, modelo botânico e taxonômico. Assim como os vegetais podiam ser classificados em gêneros e espécies, as doenças eram percebidas em seus sintomas, sua externalização, e a medicina teria o papel de distribuí-las num quadro. 
Para tanto, aplicou-se questionários médicos. Precisava-se ter o conhecimento de tudo, o maior número de informações. Um poder exercido através de investigação, de escutas, de instigação e revelação. O dizer sexual era necessário, era incitado e anotado.

Um poder que desvela um prazer no investigado. O prazer sexual é provocado, incitado, manifestado e, posteriormente, anotado. Trata-se do duplo efeito do poder, este incita o prazer, a sua manifestação, para que através dele possa exercer um controle. O prazer sexual é seduzido a se manifestar, para ser capturado, posteriormente.

O objetivo não era condenar as sexualidades periféricas, e sim geri-las, gerenciá-las. $\mathrm{O}$ dizer sexual assume o papel de fornecedor do material interpretativo para o controle. $\mathrm{O}$ controle das sexualidades, através do mapeamento das sexualidades ilegítimas. As diversas formas de sexualidade são expostas, detalhadas e atravessadas pelo poder.

Para a realização do referido controle era necessário dados para o conhecimento do objeto, material este fornecido pelo dizer sexual, pela incitação da fala sobre o sexo. Entretanto, o conhecimento sobre o objeto não bastava, para este ser controlado era necessário especificar, mapear, catalogar as múltiplas sexualidades.

Assim, destaca-se que as sexualidades múltiplas foram construídas a partir de uma estrutura de poder e verdade, qual seja: o dispositivo de sexualidade, responsável pela criação da ideia de sexo, sustentando-o como um elemento natural, biológico e coerente, conforme analisado anteriormente. Trata-se da inversão realizada por Foucault, a partir da qual, inferese que o sexo é um elemento criado, produzido, atravessado pelo poder.

Precisava-se controlar a anormalidade, a patologia. Era necessário identificar aqueles que não se amoldavam à lógica heterossexual. Estes precisavam ser especificados, catalogados, para serem controlados. Desta forma, criou-se as sexualidades periféricas, múltiplas. Estas são produtos do mecanismo de poder incidente sobre a vida.

A categorização sexual, a partir da criação e especificação das sexualidades periféricas, das perversões; como um instrumento de controle, de redução de formas de vidas sexuais. O produto factual do dizer sexual do indivíduo, quando semelhante ao de outro, é emoldurado em uma sexualidade. O indivíduo e sua vida sexual estão petrificados em uma definição externa, em uma definição do incomensurável.

Há, portanto, uma redução de singularidades. A vida do indivíduo é encaixada, emoldurada, moldada em um padrão de sexualidade, ou melhor, na própria sexualidade. 
Trata-se de um nítido apagamento de formas de vidas. O indivíduo deve ser encaixar em uma gaveta pré-fabricada.

O dispositivo de sexualidade toma os corpos como seu objeto e instrumento de poder. Investe os corpos com a ideia de sexo, como elemento biológico, imutável. Assim, produz corpos sob a égide da lógica que prega a coerência sexual, a integridade heterossexual. Produz corpos sexualizados, identificados através de sua sexualidade. Nas palavras de Butler (2008, p. 98): "[...] a sexualidade toma corpos como seu instrumento e objeto, o lugar em que ela consolida, enreda e estende seu poder.".

As sexualidades múltiplas, perversões, são incitadas, criadas e fixadas nos indivíduos, em seus corpos. Há uma fixação da categoria sexual criada no corpo do indivíduo. A partir desta, o indivíduo passa a ser identificado através de sua sexualidade. O indivíduo passa a ter uma identidade sexual, criada para medir a sua vida. Não pode ser livre, não! Precisa se amoldar, ser categorizado, especificado, para que o seu perigo possa ser mantido em controle, para que o poder próprio à sexualidade o controle de forma mais fácil, útil e eficaz.

Assim como o sexo, criam-se as sexualidades periféricas. Trata-se de uma das características do mecanismo de poder vigente, que atua através da criação do objeto que pretende regular. Produz-se as sexualidades múltiplas, as perversões, com fins de controle, de regulação, gerenciamento.

Tal concepção diverge, entretanto, com o sustentado por Butler (2008), quem sustenta que a criação e o controle não se tratam de momentos diferentes. Não se cria o sexo, não se cria as sexualidades periféricas para que estas depois sejam reguladas. A criação e a regulação ocorrem ao mesmo tempo, uma vez que para a filósofa a regulação é sempre produtiva. Em suas palavras (2008, p. 96):

Não é como se o regime regulador primeiro controlasse seu objeto e então o produzisse ou primeiro o produzisse para então controlá-lo; não há um intervalo temporal entre produção e a regulação do sexo; elas ocorrem ao mesmo tempo, pois a regulação é sempre geradora, produzindo o objeto que ela alega apenas descobrir ou encontrar no campo social em que opera.

Destaca-se, portanto, que o dispositivo de sexualidade para controlar as sexualidades múltiplas, as sexualidades que não se amoldam à lógica heterossexual, criou-as, especificouas e as nomeou. Foi necessário produzir sexualidades periféricas, pautadas em um padrão também produzido, qual seja: o sexo em aspectos biológicos, heterossexuais. 
Identifica-se, assim, uma dupla criação atinente às categorias sexuais. Primeiro, a criação do sexo pelo dispositivo de sexualidade. O sexo na concepção biológica, imutável, como pré-condição para a sexualidade. Um sexo dotado de naturalidade, o qual origina a heterossexualidade, também considerada natural.

Segundo, a criação das sexualidades periféricas pautadas na primeira criação. Tais sexualidades foram criadas tendo como base a concepção biológica do sexo, a concepção que prega como normal o casal dito heterossexual, a relação marcada pela penetração falocêntrica. Aquilo que fugir a esta lógica deve ser identificado, controlado, regulado.

Infere-se, portanto, que as sexualidades periféricas possuem como fundamento o sexo, em sua concepção biológica construída. Este é considerado o paradigma para a identificação e classificação de formas de vidas sexuais dissidentes com a lógica dominante.

As sexualidades múltiplas, perversões, são incitadas, criadas e fixadas nos indivíduos, em seus corpos. Há uma fixação da categoria sexual criada no corpo do indivíduo. O indivíduo passa a ser identificado através de sua sexualidade. Conforme citado anteriormente, para se conhecer o indivíduo, pergunta-se: que ser sexual é você?

A partir do século XIX, a dita homossexualidade passou a ser considerada uma espécie, imersa em uma caça, termo foucaultiano, às sexualidades periféricas, que ocasiona a incorporação das perversões e a especificação dos indivíduos. Nas palavras de Foucault (2014, p.47-48):

O homossexual do século XIX torna-se uma personagem: um passado, uma história, uma infância, um caráter, uma forma de vida; também é morfologia, com uma anatomia indiscreta e, talvez, uma fisiologia misteriosa. Nada daquilo que ele é, no fim das contas, escapa à sua sexualidade.

Desta forma, o que parecia antes um abrandamento da repressão sexual, através do dizer, do falar sobre a sexualidade, da ciência do sexo; mostra-se como um mecanismo eficaz de dominação, sujeição. Trata-se de um mecanismo de poder e verdade que classifica os indivíduos em categorias, fixando-as em suas próprias identidades; produtor do seu próprio objeto de regulação, o sexo e as sexualidades múltiplas (CIRINO, 2007). Assim, através desta dupla criação, os indivíduos são categorizados sexualmente, suas vidas sexuais são trancafiadas, silenciadas e moldadas, para fins de controle, gerenciamento. Um controle útil e eficaz.

Em linhas de conclusão, pôde-se identificar no presente capítulo uma estrutura de poder e verdade construída sobre o sexo. Trata-se de um dispositivo de poder, o dispositivo de 
sexualidade, responsável pela criação da ideia de sexo, este como um elemento dotado de uma naturalidade. Uma verdade construída sobre o sexo e sexualidade, aquele como um fator biológico, imutável e intrínseco ao individuo; em relação ao qual a sexualidade derivaria. Um dispositivo de poder que encapuza a construção do sexo e da sexualidade, naturalizando-os a partir da concepção biológica, sustentada como a dotada de normalidade.

Defende-se que se trata de um poder que se manifesta através de dois dos formatos de poder destacados por Foucault, poder disciplinar, incidente sobre o corpo, e biopolítica das populações, constituintes do chamado biopoder, um poder positivo, empreendedor, onipresente.

É com base na verdade construída em relação ao sexo, o sexo biológico, que a concepção naturalizada de sexualidade é formada. Esta como uma derivação lógica e coerente do sexo "natural" de cada indivíduo. Um sexo e uma sexualidade que define o indivíduo, que passa a ser um sujeito sexual.

A partir da lógica natural e binária do sexo, produz-se a ideia de sexualidades normais e desviantes, estas como as que não seguem o padrão binário "natural", o padrão biológico "heterossexual". Por isso merecem ser criadas, especificadas e incorporadas nos indivíduos, identificando-os, com fins de gerenciamento e controle. Trata-se de uma lógica de poder e verdade construída sobre o sexo, diretamente relacionada com a construção da ideia naturalizada de sexualidade e do sujeito sexual.

\section{ADOÇÃO HOMOPARENTAL E A REPRODUÇÃO DE RELAÇÕES DE PODER}

Produziu-se a concepção de sexualidades divergentes como anormais, e em que medida a necessidade de reafirmação de uma adoção homoparental como a materialização da garantia do melhor interesse de uma criança é derivado ainda dessa imputação de anormalidade em relacionamentos, em famílias constituídas por pessoas do mesmo sexo.

É interessante perceber como até mesmo a legislação pátria continua a reproduzir essa hierarquia, mais especificamente a lei 12010/2009, que estabeleceu novas diretrizes à prática adotiva, inserindo a garantia da convivência familiar da criança e do adolescente com a família natural, sendo a adoção aplicada somente após o esgotamento das possibilidades de reintegração familiar, assim como a tutela ou guarda. 
Todavia, a nova legislação não trata da adoção homoparental. Interessante e importante perceber que este silêncio possui uma origem e justificativa, conforme o que já foi destacado nas linhas em que se expôs a teoria de Michel Foucault.

Felizmente, no âmbito do poder judiciário é possível se identificar o reconhecimento da adoção homoparental, como a materialização do melhor interesse da criança. Tal reconhecimento só foi permitido a partir da decisão do STF, em 2011, por meio da Ação de Descumprimento de Preceito Fundamental - ADPF - 132 e a Ação Direta de Inconstitucionalidade - ADI - 4277, que reconheceu a união estável entre pessoas do mesmo sexo, consequentemente a família homoparental.

Foi com a referida decisão do STF, que houve a legitimação jurídica de inúmeras decisões de magistrados pelo país que concederam a adoção homoparental, assim como a alteração das decisões dos magistrados que não concediam, ainda que a referida adoção garantisse o melhor interesse da criança; à luz do art. $39, \S 2^{\circ}$ do ECA, que prevê que só podem adotar conjuntamente aqueles que fossem casados civilmente ou que contraíssem união estável, desde que comprovada a estabilidade da família. E foi a partir da referida decisão do STF que tais requisitos foram preenchidos, permitindo a aplicação da adoção homoparental.

Em linhas de conclusão, deve-se lembrar do fenômeno da constitucionalização do Direito Civil, no sentido de que o mesmo passou a ser irradiado por normas e princípios constitucionais, sendo marcado por valores como dignidade, igualdade e solidariedade. Pautado em tais valores, e considerando o que foi discutido ao longo da presente atividade, não há óbice que tenha fundamento contra a adoção homoparental, desde que esta represente a garantia do melhor interesse da criança a ser adotada.

Trata-se principalmente da garantia dos direitos da criança, assim como da garantia do direito à igualdade e dignidade de casais homoafetivos em não serem tratados de forma desigual e de forma preconceituosa em comparação com a adoção de casais heterossexuais.

\section{CONSIDERAÇÕES FINAIS}

A partir do presente estudo, buscou-se problematizar a essência do questionamento acerca da adoção homoparental ser um instituto que tenha o potencial de garantir o melhor interesse da criança, com base na ideia de que o próprio questionamento muito já representa 
no campo de relações de poder e exclusão despejados sobre a vida de pessoas que não reproduzem a lógica heteronormativa

Inicialmente, expõe-se o princípio do melhor interesse da criança, a partir de um olhar civilista, pautado em doutrina e análise principiológica. Defende-se que não há óbices que o referido princípio seja concretizado em uma adoção homoparental, desde que os variados requisitos estejam presentes na situação concreta, assim como em qualquer outro processo de adoção, homoparental ou não. Logo, a concretização do referido princípio está para além da orientação sexual dos pais que se projetam na expectativa de adotar.

Em uma segunda seção, e sem dúvidas mais extensa, apresentou-se a teoria de Michel Foucault, mais especificamente o seu dispositivo de sexualidade, baseado principalmente na sua obra história da sexualidade: vontade de saber (2014), a partir da qual se sustenta a ideia de que a sexualidade é um produto de relações de poder, atravessada por saberes que também representam poderes, saber-poder, como a medicina.

Por meio do discurso médico, extraiu-se verdades em linhas confessionais, um controle do corpo e de vidas, que teve como resultado a produção de uma sexualidade anormal e, por consequência, sexualidades divergentes, consideradas anormais e periféricas, divergentes.

Defende-se que há uma herança da referida anormalidade produzida e distribuída sobre os corpos de indivíduos que não reproduzem a linha heteronormativa de poder. Como um elemento dessa herança, o preconceito, marginalizações, exclusões efetuadas sobre os corpos das pessoas identificadas como LGBTIQ+, ao ponto de precisarmos explicar o óbvio, de refletir sobre o que não deveria sequer ser discutido mais, como a legitimidade de um casa homoafetivo adotar um filho e garantir uma vida digna, com amor e com a garantia e proteção de todos os seus direitos enquanto criança, garantindo o melhor interesse da criança ao mesmo.

Em um último momento, felizmente, destaca-se a tendência jurisprudencial pátria, que está seguindo uma linha de legitimidade da adoção homoparental, baseada principalmente na decisão do STF, que reconheceu a união homoafetiva entre pessoas do mesmo sexo, produzindo efeitos no âmbito do Direito Familiar e Sucessório.

\section{REFERÊNCIAS BIBLIOGRÁFICAS}


BRASIL. Constituição (1988). Constituição da República Federativa do Brasil. Brasília, DF: Senado Federal: Centro Gráfico, 1988.

BRASIL. Lei no 8.069, de 13 de julho de 1990. Dispõe sobre o Estatuto da Criança e do Adolescente e dá outras providências. Diário Oficial [da] República Federativa do Brasil, Brasília, DF, 16 jul.

BRASIL. Lei no 12.010, 29 de jul. de 2009. Dispõe sobre adoção; altera as Leis nos 8.069, de 13 de julho de 1990 - Estatuto da Criança e do Adolescente, 8.560, de 29 de dezembro de 1992; revoga dispositivos da Lei no 10.406, de 10 de janeiro de 2002 - Código Civil, e da Consolidação das Leis do Trabalho - CLT, aprovada pelo Decreto-Lei no 5.452, de 10 de maio de 1943; e dá outras providências. Disponível em: < http://www.planalto.gov.br/CCIVIL/_Ato2007-2010/2009/Lei/L12010.htm>. Acesso 6 de setembro de 2020.

BRASIL. Supremo Tribunal Federal. Ação Direta de Inconstitucionalidade n. 4.277 Distrito Federal. Relator: Ministro Ayres Britto. Brasília, maio 2011.

BRASIL. Supremo Tribunal Federal. Arguição de descumprimento de preceito fundamental n. 132/RJ. Requerente: Governador do Estado do Rio de Janeiro. Relator: Min. Ayres Britto. Diário da Justiça Eletrônico, 13 out. 2011.

BUTLER, Judith. Inversões Sexuais. In: Poder, normalização e violência. Incursões foucaultianas para a atualidade, por Org. Izabel C. Friche Passos. Belo Horizonte: Autêntica, 2008 .

BUTLER, Judith. Problemas de gênero - Feminismo e subversão da identidade. $7^{\mathrm{a}}$ ed. Rio de janeiro: Civilização Brasileira, 2014.

CIRINO, Oscar. O desejo, os corpos e os prazeres em Michel Foucault. Mental, Barbacena, v. $5, \quad$ n. $8, \quad$ jun. 2007. $\quad$ Disponível $\quad$ em http://pepsic.bvsalud.org/scielo.php?pid=S167944272007000100006\&script=sci_arttex.

Acesso em 19 set. 2020.

DELFINO, Morgana, o Princípio do Melhor Interesse da Criança e o Direito à Convivência Familiar: os efeitos negativos da ruptura dos vínculos conjugais. Disponível em:

$<$ http://www3.pucrs.br/pucrs/files/uni/poa/direito/graduacao/tcc/tcc2/trabalhos2009_1/morgan a_delfino.pdf $>$.

FONSECA, Márcio Alves da. Michel Foucault e o Direito. São Paulo: Max Liminad, 2002.

FOUCAULT, Michel. História da sexualidade I: A vontade de saber. Trad. Maria Thereza da Costa Albuquerque e J. A. Guilhon Albuquerque. 1a ed. Rio de Janeiro/ São Paulo: Paz \& Terra, 2014a. 
FOUCAULT, Michel. Microfísica do Poder. 29ª reimpressão. São Paulo: Graal, 2011.

FOUCAULT, Michel. Problematização do Sujeito: Psicologia, Psiquiatria e Psicanálise. In: Ditos e Escritos I. $3^{\circ}$ ed. Rio de Janeiro: Forense Universitária, 2014b.

LÔBO, Paulo. Direito Civil: famílias. $3^{\text {a }}$ ed. São Paulo: Saraiva, 2010.

SALIH, Sara. Judith Butler e a Teoria Queer. 1ª ed. São Paulo: Autêntica, 2013.

SGRECCIA, Elio. Manual De Bioética: I - Fundamentos e Ética Biomédica. 2a ed. São Paulo: Edições Loyola, 2002.

SGRECCIA, Elio. Manual De Bioética: II - Fundamentos e Ética Biomédica. $2^{\circ}$ ed. São Paulo: Edições Loyola, 2004. 